\title{
Three-dimensional Evaluation of the Placenta: Review of the Literature
}

\author{
Stavros Natsis, Panos Antsaklis, Aris Antsaklis, Asim Kurjak
}

\begin{abstract}
The introduction of the three-dimensional (3D) ultrasound made feasible the quantitative and qualitative evaluation of the placenta's characteristics like the volume, the surface rendered imaging, the vascularization and the blood flow. These novel techniques may assist the early detection of pregnancies at high risk for fetal growth restriction (FGR), pre-eclampsia (PET) and pregnancy-induced hypertension $(\mathrm{PIH})$ and help clinicians to detect pregnancies at risk earlier and to assess new therapeutic strategies in order to prevent adverse pregnancy outcomes. However, in this new technique there are still limitations regarding the assessment of the placenta employing 3D ultrasound in everyday clinical practice. In the following article, we perform a review of the literature regarding the importance of 3D evaluation of the placenta in pregnancy.
\end{abstract}

Keywords: Three-dimensional ultrasound, Three dimension, Placental volume.

How to cite this article: Natsis $S$, Antsaklis $P$, Antsaklis $A$, Kurjak A. Three-dimensional Evaluation of the Placenta: R eview of the Literature. Donald School J Ultrasound Obstet Gynecol 2013;7(1):73-79.

\section{Source of support $\mathrm{Nil}$}

Conflict of interest: None declared

\section{INTRODUCTION}

Pregnancy associated problems like intrauterine growth retardation (IUGR) or pre-eclampsia (PET) are mainly caused by a disturbed placental function. Current models suggest that these problems are related to an impaired invasion of fetal trophoblastic cells in the maternal decidua, which will leads to an impeded transformation of the spiral arteries into vessels of low resistance. ${ }^{1} \mathrm{~T}$ his causes reduced blood flow and accordingly leads to hypoxic damage of the endothelial vessels, initiating a range of disorders including placental infraction, increased maternal blood pressure (pregnancy-induced hypertension, $\mathrm{PIH}$ ) and fetal growth restriction (FGR) among others.

Conventional two-dimensional (2D) ultrasound has been widely used for the evaluation of the placenta during pregnancy. This 2D evaluation includes the assessment of the morphology and anatomy of the placenta, identification of its location and evaluation of other placental issues, such as quality of implantation, structural or functional anomalies, placental size and more recently study of color/power and pulsed Doppler characteristics of the placenta. ${ }^{2,3}$
The earlier in pregnancy we identify a risk factor for obstetric complications, the higher the chance that we may find a treatment. Identifying risk factors for PET and IU GR in the first trimester of pregnancy has been a great challenge in obstetrics the last decade. N ew evidence show that threedimensional (3D) evaluation of the placenta may be a possible method to detect impaired trophoblastic invasion in the first trimester might be. 3D ultrasound has the potential to provide improved visualization of the fetal anatomic morphology compared to the conventional 2D imaging. 3D ultrasound and power Doppler offer a more objective and more detailed method of evaluating placental volume and its vascular network. In 1984, the first placental volumes acquired via sonography were conducted by B rinkley et al. ${ }^{4}$ Since, then the progress of technology and the development of 3D sonography (3DUS) imaging assisted by computer technology, has made possible the measurement and calculation of fetal and placental volumes accurately and quickly. This method has been standardized and implemented in everyday practice. W hat is more 3D power Doppler offers more information on the placental anatomy and function. The Doppler parameters derived from 3D interrogation of the placenta include the vascularization index (VI), the flow index (FI) and the vascularization flow index (VFI).

A im of this paper is to review all available studies regarding 3D ultrasonographic assessment of the placental morphology, placental volume measurement, and placental vascularization and blood flow.

\section{Evaluation of Placental \\ Abnormality Using 3D Ultrasound}

In most cases an exact diagnosis of placental abnormalities can be made using only the $2 \mathrm{D}$ ultrasound. However, using the 3D ultrasound, more detailed information on placental abnormalities can be obtained, especially visualization of the continuity and curvature. There have been two reports on placental diagnosis of placental abnormalities using 3D surface rendered imaging. $\mathrm{H}$ ata et al in $2004^{5}$ investigated six cases with placental abnormalities and found that visualization of the continuity and curvature of structures was more easily accomplished with the 3D sonography than the 2D. In addition, A bramowicz et al suggested that 3D 
surface rendered images provide an entirely new visual experience not only for the examiner, but also for patients and their families, owing to the near-photographic depiction of the placental abnormality in utero. ${ }^{6}$

\section{Volume Measurement Using 3D Ultrasound}

Volume measurements using 3D ultrasound methods are much more accurate than the methods using the 2D ultrasound for regular and irregular shaped objects. Riccabona et al observed that 3D measurement error was only $6.4 \pm 4.4 \%$ whereas $2 \mathrm{D}$ error reached $12.6 \pm 8.7 \%$ when compared the accuracy of ultrasound for volume measurement. ${ }^{7}$ There are three techniques for the placental volume assessment; that is (a) the multiplanar method, (b) the V OCAL (virtual organ computer-aided analysis) method and $(c)$ the XI VOCAL (extended imaging VOCAL) method. Nowac et al in 2007 in a prospective cross sectional study involving 37 pregnant women, evaluated placental volumes in early pregnancy using both multiplanar and VOCAL methods and comparing the results. ${ }^{8}$ This study showed strong correlation between placental volume measured by the VOCAL and the multiplanar methods which are considered to be concordant. A nother study by Cheong et al in 2010 showed that XI V OCA L method to be inferior to V OCA L in terms of reliability and validity. ${ }^{9} \mathrm{~T}$ he better results of the VOCAL mode can be explained by its ability to allow finer contouring of the object of interest and easier subsequent modification of the contour. In contrast the current XI V OCA L mode applies a fixed slice interval and does not take into account the highly variable contour of an irregular subject.

There are several studies regarding the volume of the placenta and the prediction of the birth weight percentile. Plasencia et al in a prospective study involving 3,104 singleton pregnancies suggested that combined measurement of placental volume and serum pregnancy associated plasma protein A (PAPP-A) can improve the prediction of small (SGA) or large for gestational age (LGA) fetuses, compared to the prediction provided by maternal characteristics alone. ${ }^{10}$ They found that an algorithm combining maternal characteristics with either placental volume or maternal serum PA PP-A can potentially identify about $30 \%$ of pregnancies with $S G A$ or $L G A$, with a false positive rate (FPR) of $10 \% .{ }^{10} \mathrm{H}$ owever, there was no significant improvement in the performance of screening for SGA or LGA neonates by the addition of placental volume in the combination of maternal factors and serum PAPP-A. There are also two previous studies which have studied the prediction of SGA from first trimester measurements of placental volume. ${ }^{11,12} \mathrm{H}$ afner et al examined 2,489 singleton pregnancies at 11 to $13^{+6}$ weeks of their pregnancy and reported that the detection rate of SGA by measurement of placental volume alone was $27 \%$, with a FPR of $10 \% .{ }^{11}$ Similarly, Law et al studied 601 pregnancies and reported that the measurement of placental volume at 11 to $13^{+6}$ weeks identified $23 \%$ of SGA neonates, with a FPR of $10 \%$ and the prediction rate was not improved by the measurement of uterine artery D opplers or fetal crown rump length $(C R L){ }^{13}$

There are plenty of studies regarding the prediction of adverse pregnancy outcomes including PET and pregnancyinduced hypertension, using placental volume measurement in the first trimester of pregnancy, but their results do not appear to agree on the prognostic value of placental volume measurement. M etzenbauer et al in a study involving 2,863 singleton pregnancies suggested that the median placental quotient (quotient from placental volume and $C R L$ ) in the chromosomally abnormal fetuses group, was significantly lower than that in the normal fetuses and they concluded that the assessment of placental volume may prove to be useful in first trimester risk assessment for chromosomal anomalies. ${ }^{14} \mathrm{O}$ bido et al suggested that the value of placental volume measurement and the interpretation of the results from the measurements depend on the pregnancy complication being studied. ${ }^{18}$ In particular they found placental volumes to be lower in the pregnancies with PIH and SGA compared with the placentas of pregnancies with PET. This is consistent with studies that have demonstrated different morphologic characteristics of the placenta in pregnancies with growth restriction compared with PE. ${ }^{18}$ However as a screening tool, placental volume was associated with poor predictive efficiency even for SGA and PIH in that study. O $n$ the other hand, Haffner et al stated that placental quotient $(\mathrm{PQ})$ is insufficient for the screening of SGA, PET and PIH in low-risk populations. ${ }^{11}$ They also reported that the placentas of women with pathologic uterine perfusion in the second trimester of pregnancy are al ready remarkably small at the end of first trimester. ${ }^{20}$

Several studies about the reproducibility of the placentas' volume measurement are available. ${ }^{19-25}$ Bujold et al in 2009 concluded that evaluation of placental volume between 11 and 14 weeks of pregnancy is a feasible and reliable method. ${ }^{22}$ In an other study by Huster et al in 2010, it was confirmed that the 3D measurements of the placental volumes are highly reproducible with the intraobserver and the interobserver correlations greater than 0.75 , which is considered to be a good agreement. ${ }^{23}$ Deurl oo et al in 2006 in his study about reproducibility of 3D sonographic measurements of placental volume concluded that this method is highly reproducible both by the same and by 
Three-dimensional Evaluation of the Placenta: Review of the Literature

different operators. ${ }^{24} \mathrm{On}$ the other hand, Chen et al which noted that the intra- and interobserver agreement of placental volume measured by 3D ultrasound is relatively poor, which is reflected in the wide limits of agreement of acceptance in each case. $^{25}$

\section{D Power Doppler Analysis of the Placenta}

Conventional Doppler ultrasound study has been used as a noninvasive method to assess human fetoplacental circulation, by examining blood flow in the umbilical artery. Increased umbilical arterial resistance and reduced umbilical arterial flow studied by conventional Doppler ultrasound can be used as a predictor of adverse pregnancy outcome in high risk pregnancies. Power Doppler ultrasound uses the amplitude of the signals received to represent the number of moving blood cells. It has been found to be superior to frequency - based color D oppler ultrasonography, especially in low blood flow situations (low velocities), and has the potential to detect alterations in blood flow. In recent years power Doppler ultrasonography combined with 3D ultrasound (3D power Doppler) has been promising when it comes to evaluating morphological features of the placenta and the quantification of total blood flow in the placental vascular network in ongoing pregnancy. ${ }^{26} \mathrm{M}$ ore recently, 3D power Doppler indices such as, (a) VI which means the proportion of the volume showing a flow signal in the placenta; (b) FI which is the average flow signal intensity inside the placenta; (c) vascularization flow index (VFI) which is a combination of the information concerning vessel presence and the level of flow obtained by multiplying $\mathrm{V} \mathrm{I}$ and $\mathrm{FI}$, have been used to assess placental perfusion. Differences in these indices have been shown to exist between the different populations that are studied and the different gestational ages. ${ }^{27} \mathrm{~W}$ ith the exception of first trimester of pregnancy, 3D power Doppler technology does not allow the evaluation of the whole placental vascular tree. ${ }^{26,28} \mathrm{To}$ avoid this technical difficulty, M erce et al have suggested a different method based on 3D power Doppler which they called 'placental vascular biopsy' or 'placental vascular sonobiopsy' (PVS) or 'virtual placental biopsy' and have confirmed with their studies its clinical reproducibility. ${ }^{29,33}$ For the measurement of PVS the power Doppler window is placed over the placenta, including its total thickness, from the basal to chorionic plates. ${ }^{30}$ The spherical 3D volume is obtained between the basal and chorionic plates. The VOCAL program automatically calculates gray scale and color values (VI, FI and VFI) from the acquired sphere. A sequence of three placental sections separated by successive rotation of $60^{\circ}$ is obtained and 3 or 4 spherical sampling sites are chosen in each plane.
Several studies have been conducted to determine the reference values and the ranges of the VI, FI and VFI during pregnancy. Paula et al in a prospective study of 295 singleton, low-risk women found that the placental vascular indicesestimated by 3D power Doppler ultrasonography presented constant distribution throughout gestation, despite the significant increase of the placental volume. ${ }^{31}$ This finding suggests that placental vascularization may increase proportionally to the organ volume, contributing to maintaining the placental vascular indices constant throughout gestation. Similar findings were observed by Guiot et al.$^{27}$ The results of these studies are considerably different when compared to other studies reported in the literature. Y u et al in 2003 in a study involving 100 normal placentas found that both VI and VFI increased throughout pregnancy. ${ }^{32}$ In a later study by Merce et al it was demonstrated that 3D indices correlated significantly with gestational age, although each of them exhibited different behavior. ${ }^{33} \mathrm{~W}$ hereas $\mathrm{FI}$ increased in a linear and progressive manner along gestation, the VI increased up to 30 weeks maintaining a plateau up to the 37th week and decreasing after that week of pregnancy. TheV FI reflected the behavior of both indices. One possible explanation for these differences in the previous studies is the different sampling method of volume acquisition in the placenta. For example, $Y u$ et al did not describe the volume applied and the place selected to obtain a representative sample of placental vascularization, while M erce et al used the previous reported method of sonobiopsy. A nother explanation is the different machines and the machine setting used. There are investigations which provide evidence that machines settings affect VI, FI and VFI calculations. ${ }^{34}$ It has been also demonstrated that the position of the placenta attachment in the uterine cavity may affect the measurements. ${ }^{35}$ Some authors have stressed that only anterior placentas should be included in their studies to avoid the risk of D oppler signal attenuation. ${ }^{30}$ J ones et al suggested that when undertaking 3D ultrasound and power Doppler angiography (3D-PDA) several technical aspects must be considered and she documented that depth depended attenuation of the signal needs to be accounted for in any in vivo work where the probe is not in direct contact with the tissue of interest. ${ }^{36}$

\section{Vascularization Indices and Adverse Pregnancy Outcome Prediction}

Several articl es havestudied the importance of first trimester placental vascularization indices for the prediction of adverse pregnancy outcomes (Table 1). O deh et $\mathrm{al}^{37}$ in a study with 308 pregnant women during 11 to $13^{+6}$ weeks of gestation 
Table 1: Studies regarding usefulness of 3D measurement of the placenta in first trimester of pregnancy for the prediction of adverse pregnancy outcome ${ }^{15-17}$

\begin{tabular}{lllllll}
\hline Study & Year & N & Gestation & Parameter used & Prediction & Screening \\
\hline Schuchter $^{12}$ & 2001 & 380 & $11-14$ & PQ & PIH, PET, FGR & Useful \\
Hafner $^{20}$ & 2001 & 1060 & $11-13$ & PV, PQ & Uterine perfusion & Useful \\
Metzenbauer $^{14}$ & 2002 & 2863 & $10-13$ & PQ & Chromosomal abnormalities & Useful \\
Metzenbauer $^{15}$ & 2002 & 1476 & NG & PQ & LBW & Promising \\
Hafner $^{11}$ & 2006 & 2489 & $11-13$ & PQ & PIH, PET, FGR & Insufficient \\
Rizzo $^{16}$ & 2008 & 348 & $11-14$ & PV & PET & Useful \\
Law $^{13}$ & 2009 & 619 & $11-13$ & PV & SGA & Useful \\
Rizzo $^{38}$ & 2009 & 84 & $11-14$ & PV+PAPP-A & Pregnancy outcomes & Insufficient \\
Schwartz $^{17}$ & 2010 & 135 & $11-14$ & PQ & PET, SGA & Promising \\
Plasencia & 2011 & 3104 & $11-13$ & PV+PAPP-A & Birth weight & Useful \\
Obido $^{18}$ & 2011 & 388 & $11-14$ & PV,VI,FI,VFI & PIH, PET, FGR & Insufficient \\
Odeh $^{37}$ & 2011 & 308 & $11-14$ & PV,VI, FI,VFI & SGA, PET & Insufficient \\
\hline
\end{tabular}

NG: Not given; P Q: Placental quotient; PV: Placental volume; PIH: Pregnancy induced hypertension; FG R: Fetal growth restriction; LBW: Low birth weight; SGA: Small for gestational age fetus; PET: Pre-eclampsia; PAP P-A: Pregnancy associated plasma protein A

suggested that VI may be of some potential in detection of $\mathrm{PIH}$. O bido et al ${ }^{18}$ found that the mean vascular indices of first trimester placentas were lower in pregnancies that subsequently developed PET compared to pregnancies who did not develop PET. Inaddition those pregnancies with both PET and SGA had a significantly lower FI compared tothe control group of unaffected pregnancies. The prediction models forPET using theseindices w erehow ever, associated with only modest discriminatory ability. Thesefindings were not as significant as previous studies, which had suggested better prediction of PET and SGA using placental volumes and vascularization indices. R izzo et al ${ }^{38}$ in a study with 84 singl eton pregnancies which had low PA PP-A levels during thefirsttrimester of pregnancy found that among pregnancies with low serum PAPP-A levels, significant decrease in the 3D power D oppler vascularization indices at 11 to $13^{+6}$ w eeks was shown in those pregnancies who had low PAPP-A but al so developed IU GR fetuses. A second finding of this study was the significant association between the degree of reduction in the $3 \mathrm{D}$ placental Doppler indices and theseverity of thegrowth defects at birth. In another study B ozkurtet al ${ }^{39}$ reported that VI values in the placenta at 11 to 14 weeks of gestation show a positivelinear correlation with thenewborn weight.

Table 2: Studies regarding the value of different parameters from 3D assessment for the prediction of adverse pregnancy outcome

\begin{tabular}{|c|c|c|c|c|c|c|c|}
\hline Study & Year & $\mathrm{N}$ & Week & Population & Parameter & Prediction & Screening \\
\hline Merce $^{33}$ & 2005 & 99 & $14-40$ & Normal & $\mathrm{PB}, \mathrm{VI}, \mathrm{FI}, \mathrm{VFI}$ & Correlation with GA & Useful \\
\hline Zalud $^{40}$ & 2007 & 199 & $14-25$ & Normal & VI, FI, VFI & $\begin{array}{l}\text { Definition of indices in } \\
\text { 2nd trimester }\end{array}$ & Useful \\
\hline Guiot $^{27}$ & 2008 & 45 & $23-37$ & Normal \& FGR & $\mathrm{VI}, \mathrm{FI}, \mathrm{VFI}$ & FVW in Normal and IUGR & Useful \\
\hline Zalud $^{41}$ & 2008 & 199 & $14-25$ & Normal & VI, FI, VFI & $\begin{array}{l}\text { Correlation with maternal } \\
\text { age and parity }\end{array}$ & $\begin{array}{l}\text { Parity influences } \\
\text { indices }\end{array}$ \\
\hline De Paula ${ }^{31}$ & 2009 & 295 & $12-40$ & Normal & VI, FI, VFI & Quantitative analysis of PV & $\begin{array}{l}\text { Placental indices } \\
\text { have constant } \\
\text { distribution }\end{array}$ \\
\hline Rizzo 38 & 2009 & 84 & $11-14$ & Low PAPP-A & PV, VI, FI, VFI & Pregnancy outcome & $\begin{array}{l}\text { Altered 3D } \\
\text { placental indices, } \\
\text { useful }\end{array}$ \\
\hline Noguchi ${ }^{30}$ & 2009 & 208 & $12-40$ & Normal & PB, VI, FI, VFI & FGR & Useful \\
\hline Tuuli ${ }^{43}$ & 2010 & 120 & $11-14$ & Normal & VI, FI, VFI & $\begin{array}{l}\text { Correlation of } \\
\text { indices } \pm P B\end{array}$ & $\begin{array}{l}\text { VI \& VFI more } \\
\text { reliable than FI in } \\
\text { PB }\end{array}$ \\
\hline Hafner $^{21}$ & 2010 & 383 & $11-14$ & Normal & $\begin{array}{l}\mathrm{PV}, \mathrm{PQ}, \mathrm{VI}, \mathrm{FI} \text {, } \\
\text { Uterine art. Doppler }\end{array}$ & Pregnancy outcome & $\begin{array}{l}\text { Useful for IUGR } \\
\text { and PE }\end{array}$ \\
\hline Y igiter ${ }^{44}$ & 2011 & 310 & $11-14$ & Normal & $\begin{array}{l}\text { PV, VI, FI, VFI, } \\
\text { uterine art. Doppler }\end{array}$ & $\begin{array}{l}\text { PAPP-A, IGF-1, } \\
\text { free } \beta-h C G\end{array}$ & $\begin{array}{l}\text { Significant } \\
\text { correlation }\end{array}$ \\
\hline Obido ${ }^{18}$ & 2011 & 388 & $11-14$ & Normal & PV, VI, FI, VFI & $\begin{array}{l}\text { Adverse pregnancy } \\
\text { outcomes }\end{array}$ & Useful \\
\hline
\end{tabular}

PB: Placental sonobiopsy; VI: Vascularization index; FI: Flow index; VFI: Vascularization flow index; PV: Placental volume; PQ: Placental quotient; PE: Pre-eclampsia; FGR: Fetus growth restriction; FVW: Flow velocity waveforms 
Other studies on 3DPD indices of the placenta on the later half of the pregnancy for adverse pregnancy outcomes have been conducted (Table 2). G uiot et al in $2008^{27}$ studied 45 pregnant women from 23 to 37 weeks of gestation and concluded that 3D power Doppler sonography can provide new insights about the placental pathophysiology and $\mathrm{FI}$ appears to be the most reliable index, because of its low intraplacental variability. The VI and V FI were significantly lower in pregnancies complicated by FGR and had positive end diastolic umbilical artery flow velocity waveforms while in pregnancies with absent or reversed end diastolic umbilical artery flow velocity waveforms compared with normal pregnancies, while the FI decreased only in those with absent or reversed end diastolic umbilical artery flow velocity waveforms. On the other hand Nogucchi et al ${ }^{30}$ showed that $\mathrm{VI}, \mathrm{FI}$ and $\mathrm{VFI}$ in $\mathrm{FGR}$ pregnancies decrease throughout pregnancy and suggested that the $\mathrm{FI}$ is the least reliable index despite the fact it has a low intraplacental variability. One possible explanation is the heterogenity of the study populations between these two papers.

$W$ ith respect to maternal characteristics and vascularity indices, Zalud et al in $2008^{40,41}$ found that maternal age influenced uterine spiral vasculature volume, whereas parity influenced all placental 3DPD indices. Rizzo et al ${ }^{38}$ found lower values of the vascular flow indices among women who smoked over 10 cigarettes per day. 0 bido et al ${ }^{18}$ on the other hand found that maternal smoking did not affect the placental vascular indices.

Several studies have demonstrated the reproducibility of 3DPD ultrasound placental index measurements. Several authors obtained good intra- and interobserver reproducibility employing 3DPD parameters in the placenta. ${ }^{22,30,36}$ When the visualization of the entire placental tree is not feasible a valid alternative could be placental vascular indices from PVS which show a good correlation with those of the entire placenta. ${ }^{42}$

\section{CONCLUSION}

It is well-established that PET and IUGR is caused by abnormal trophoblastic invasion and pathologic formation of the spiral arteries leading to increased placental resistance and decreased blood flow to the intervillous space. This abnormality in placentation can indirectly be measured and assessed via 2D ultrasound and more specifically through uterine artery Doppler. ${ }^{44}$ However, studies show that conventional 2D ultrasound cannot provide the same information as 3D assessment of the placenta. Indeed 3D ultrasonography offers a more direct evaluation of blood flow to the placenta, and it has been shown by many studies that it may lead to earlier recognition of placentas at risk for adverse pregnancy outcomes, such as PET and IUGR or even chromosomal abnormalities. ${ }^{43} \mathrm{We}$ are now able using this new technique to evaluate more precisely the surface of the placenta, its volume and the placental vascular tree. However, lack of standardization of a universal method that would assess placenta with 3D ultrasound, has delayed the gathering of sufficient data that would allow this method to be applied as a screening tool in everyday clinical practice. Further work is required to establish the effect of other confounding parameters before valid conclusions may be made and a better understanding of 3D power Doppler ultrasound imaging achieved. ${ }^{38} \mathrm{M}$ ore studies with standardized machine settings are needed in current practice, in order to draw safe conclusions on the usefulness of 3D assessment of the placenta.

\section{REFERENCES}

1. Pijnenborg R, B land JM, Robertson WB, Brosens I. U teroplacental arterial changes related to interstitial trophoblast migration in early human pregnancy. Placenta 1983 OctDec;4(4):397-413.

2. A bramowicz J, Sheiner E, Ultrasound of the placenta: $A$ systematic approach. Part I: Imaging placenta 2008;29;225-40.

3. M atijevic R. The placenta. In: Kurjak A, Chervenak FA (Eds). D onald school textbook of ultrasound and gynecology (2nd ed). New Delhi: Jaypee; 2008;452-64.

4. B rinkley JF, M CC allum WD , M uramatsu SK, et al. Fetal weight estimation from lengths and volumes found by 3D ultrasonic measurements. J Ultrasound M ed 1984;3:163.

5. Hata T, K anenishi K, Inusbashiri E, T anaka H, Senoh D, M anabe A, et al. Three dimensional sonographic features of placental abnormalities. Gynecol Obstet Invest 2004;57:61-65.

6. A bramowicz JS, Sheiner E. In utero imaging of the placenta: Importance for diseases of pregnancy. Placenta 2007 A pr;28(Suppl A):S14-22.

7. Riccabona M, Nelson TR, Pretorius DH. Three-dimensional ultrasound: A ccuracy of distance and volume measurements. Ultrasound Obstet Gynecol 1996;7:429-34.

8. N owak PM, Nardozza L M M, A raujo J r, Rolo LC, M oron A F. Comparison of placental volume in early pregnancy using multiplanar and VOCAL methods. Placenta 2008;29:241-45.

9. Cheong K B , L eung KY, Li TKT, Chan HY, Lee Y P, T ang HY . Comparison of inter and intraobserver agreement and reliability between three different types of placental volume measurement technique (XI VOCAL, VOCAL and multiplanar) and validity in the in vitro setting. Ultrasound Obstet Gynecol 2010;36; 210-17.

10. Plasencia W, A kolekar R, Dagklis T, V eduta A, Nicolaides K. Placental volume at 11 to 13 weeks' gestation in the prediction of birth weight percentile. Fetal Diagn Ther 2011;30:23-28.

11. Hafner E, M etzenbauer M, H ofinger D, Stonek F, Schuchter K, W aldhor $T$, etal. Comparison between threedimensional placental volume at 12 weeks and uterine artery impedance/notching at 22 w eeks in screening for pregnancy-induced hypertension, preeclampsia and fetal grow th restriction in a low risk population. UItrasound Obstet Gynecol 2006;27:652-57. 
12. Schuchter K, M etzenbauer M, Hafner E, Philipp K. Uterine artery $\mathrm{D}$ oppler and placental volume in the first trimester in the prediction of pregnancy complications. Ultrasound Obstet Gynecol 2001;18:590-92.

13. L aw LW , L ewng TY, Sahota DS, Chan LW, Fung TY, L au TK. Which ultrasound or biochemical markers are independent prediction of small-for-gestational age? Ultrasound Obstet Gynecol 2009;34:283-87.

14. M etzenbauer M, Hafner E, Schuchter K, Philipp K. Firsttrimester placental volume as a marker for chromosomal anomalies: Preliminary results from an unselected population: UItrasoun O bstet Gynecol 2002;19:240-42.

15. M etzenbauer $M$, Hafner $E$, H oefinger $D$, Schuchter $K$, Philipp $K$. A ssociation between birth weight and placental volume in the first trimester. Z G eburtsch N eonatol 2002;206:138-41.

16. Rizzo G, Capponi A, Cavicchioni 0, Vendola M, A rduini D. First trimester uterine Doppler and three dimensional ul trasound placental volume calculation in predicting pre-eclampsia. Eur J Obstet Gynecol Reprod Biol 2008 J un;138(2):147-51.

17. Schwartz N, Coletta J, Pessel C, Feng R, Timor-T ritsch IE, Parry $S$, et al. Novel 3-dimensional placental measurements in early pregnancy as predictors of adverse pregnancy outcomes. J Ultrasound M ed 2010;29:1203-12.

18. O bido A O, G oetzinger K R, Huster K M , Christiansen JK, O bido $L$, Tuuli M G. Placental volume and vascular flow assessed by 3D power Doppler and adverse pregnancy outcomes. Placenta 2011;32:230-34.

19. M ayhew TM. A stereological perspective on placental morphology in normal and complicated pregnancies. J A nat 2009 Jul;215(1):77-90.

20. Hafner $E, M$ etzenbauer $M$, Dillinger-Paller $B$, Hoefinger $D$, Schuchter K, Sommer-Wagner $\mathrm{H}$, et al. Correlation of first trimester placental volume and second trimester uterine artery Doppler flow. Placenta 2001;22:729-34.

21. Hafner $E$, M etzenbauer $M$, Stumpflen I, W alddhor T, Philipp $\mathrm{K}$. First trimester placental and myometrial blood perfusion measured by 3D power Doppler in normal and unfavourable outcome pregnancies. Placenta 2010;31:756-63.

22. Bujold M, Effendi M, Girard M, Gouin K, Forest J C, Couturier $B$, et al. Reproducibility of first trimester three-dimensional placental measurements in the evaluation of early placental insufficiency. J Obstet Gynaecol Can 2009 Dec;31(12): 1144-48.

23. Huster K, Haas K, Schoenborn J, M cV ean D, O bido A. Reproducibility of placental volume and vasculature indices obtained by 3-dimensional power Doppler sonography. J Ultrasound M ed 2010;29:911-16.

24. Deurloo K, Spreeuwenberg M, R ekoert-H ollander M, van V ugt J. Reproducibility of 3-dimensional sonographic measurements of fetal and placental volume at gestational ages of 11 to 18 weeks. J Clin UItrasound 2007;35:125-32.

25. Chen $M$, Leung $K Y$, Lee $C P$, Tang M HY, Ho PC. Placental volume measured three dimensional ultrasound in the prediction of $\alpha$-thalassemia: A preliminary report. Ultrasound Obstet Gynecol 2006;28:166-72.

26. Hafner $T, K$ urjak A, Funduk-K urjak B, B ekavac I. A ssessment of early chorionic circulation by three dimensional power Doppler. J Perinat M ed 2002;30:26-32.
27. Guiot C, Gaglioti P, O berto M, Piccoli E, Rosato R, Todros T. Is three dimensional power Doppler ultrasound useful in the assessment of placental perfusion in normal and growth restricted pregnancies? UItrasound Obstet Gynecol 2008;31:171-76.

28. M atijevic $R, K$ urjak $A$. The assessment of placental blood vessels by three dimensional power Doppler ultrasound. J Perinat M ed 2002;30:33-39.

29. Merce $L T, B$ arco MJ, Bau $S$. Reproducibility of the study of placental vascularization by three dimensional power Doppler. J Perinat M ed 2004;32:228-33.

30. Noguchi J, Hata K, Tanaka H, Hata T. Placental sonobiopsy using three dimensional power Doppler ultrasound in normal and growth restricted fetuses. Placenta 2009;30;391-97.

31. DePaula CFS, Ruano R, Campos]AD B, Zugaib M. Quantitative analysis of placental vasculature by three dimensional power Doppler ultrasonography in normal pregnancies from 12 to 40 weeks of gestation. Placenta 2009;30:142-48.

32. $\mathrm{Y} u \mathrm{CH}$, Chang $\mathrm{CH}, \mathrm{K}$ o HC, Chen W C, Chang FM . A ssessment of placental fractional moving blood volume using quantitative three dimensional power Doppler ultrasound. UItrasound Med Biol 2003;29:19-23.

33. M erce LT, B arco M, B au S, K upesic S, Kurjak A. A ssessment of placental vascularization by three dimensional power Doppler 'vascular biopsy' in normal pregnancies. Croat M ed J 2005:46:765-71.

34. Martins WP, Raine Fenning N, Ferriani RA, Nastri CO. Quantitative three dimensional power Doppler angiography: A free-flow phantom experiment to evaluate the relationship betw een color, gain, depth and signal artifact. UItrasound Obstet Gynecol 2010:35:361-68.

35. Raine-Fenning N J, N ordin N M , R anmarine K V , Campbell BK, Clewes JS, Perkins A, et al. Determining the relationship between three-dimensional power Doppler data and true blood flow characteristics: An in vitro flow phantom experiment. Ultrasound Obstet Gynecol 2008;32;540-50.

36. J ones N W, Raine-Fenning N J, M ousa HA , B radley H, B ugg G. Evaluating the intra- and interobserver reliability of threedimensional ultrasound and power Doppler angiography (3DPDA ) for assessment of placental volume and vascularity in the second trimester of pregnancy. Ultrasound Med Biol 2011;37(3):376-85.

37. Odeh M, Ophir E, Maximovsky O, Grinin V, Bornstein J. Placental volume and three dimensional power D oppler analysis in prediction of pre-eclampsia and small for gestational age between week 11 and 13 weeks and 6 days of gestation. Prenat Diagn 2011;31:367-71.

38. Rizzo G, Capponi A, Pietrolucci ME, Capece A, A rduini D. First trimester placental volume and vascularization measures by 3-dimensional power Doppler sonography in pregnancies with low serum pregnancy associated plasma protein A levels. J Ultrasound M ed 2009;28:1615-22.

39. B ozkurt N, Y igiter B, Gokaslan H, Kavak ZN. Correlations of fetal maternal outcomes and first trimester 3D placental volume/ 3D Doppler calculations. Clinical Exp Obstet Gynecol 2010;37:26-28.

40. Zalud I, Shaha S. Three dimensional sonography of the placental and uterine spiral vasculature: Influence of maternal age and parity. J Clin Ultrasound 2008;36(7):391-96. 
41. Zalud I, Shaha S. Evaluation of the uteroplacental circulation by three-dimensional Doppler ultrasound in the second trimester of normal pregnancy. J Maternal-Fetal Neonatal Med 2007 A pril;20(4):299-305.

42. Tuuli M G, Houser M, O bido L, Huster K, M acones GA, Obido A O. Validation of placental vascular sonobiopsy for obtaining representative placental vascular indices by three dimensional power Doppler ultrasonography. Placenta 2010;31:192-96.

43. Y igiter $A B, K$ avak $Z N$, D urukan $B$, Isci $H$, Uzuner $A$, Uyar $E$, et al. Placental volume and vascularization flow indices by $3 D$ power Doppler US using VOCAL technique and correlation with I GF-1, free beta-hCG , PA PP-A and uterine artery Doppler at 11 to 14 weeks of pregnancy. J Perinat Med 2011 Mar; 39(2):137-41.

44. Gebb J, D ar P. Colour D oppler ultrasound of spiral artery blood flow in the prediction of pre-eclampsia and intrauterine growth restriction. Best Pract Res Clin Obstet Gynaecol 2011 Jun;25(3):355-66.

\section{ABOUT THE AUTHORS}

\section{Stavros Natsis}

Registrar, 1st D epartment of Obstetrics and Gynecology, A lexandra Hospital University of Athens, A thens, Greece

\section{Panos Antsaklis (Corresponding Author)}

Research Fellow in Fetal and $M$ aternal M edicine, 1st Department of Obstetrics and Gynecology, A lexandra Hospital U niversity of A thens A thens, Greece, e-mail: panosant@gmail.com

\section{Aris Antsaklis}

Professor, 1st Department of O bstetrics and Gynecology, A lexandra Hospital University of A thens, A thens, Greece

\section{Asim Kurjak}

Professor, Department of Obstetrics and Gynecology, School of Health Science, Dubrovnik International U niversity, Dubrovnik, Croatia 